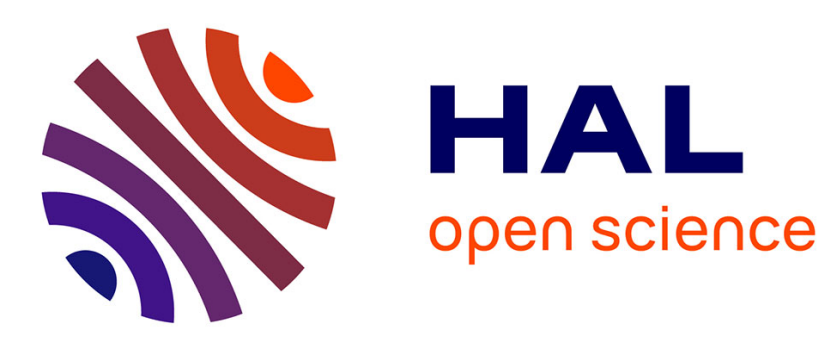

\title{
Jellyfish degradation in a shallow coastal Mediterranean lagoon
}

\author{
Raquel Marques, Marta Rufino, Audrey M. Darnaude, Frédérique Carcaillet, \\ Marie Meffre, Delphine Bonnet
}

\section{- To cite this version:}

Raquel Marques, Marta Rufino, Audrey M. Darnaude, Frédérique Carcaillet, Marie Meffre, et al.. Jellyfish degradation in a shallow coastal Mediterranean lagoon. Estuarine, Coastal and Shelf Science, 2021, 261, pp.107527. 10.1016/j.ecss.2021.107527 . hal-03415608

\section{HAL Id: hal-03415608 \\ https://hal.umontpellier.fr/hal-03415608}

Submitted on 10 Nov 2021

HAL is a multi-disciplinary open access archive for the deposit and dissemination of scientific research documents, whether they are published or not. The documents may come from teaching and research institutions in France or abroad, or from public or private research centers.
L'archive ouverte pluridisciplinaire HAL, est destinée au dépôt et à la diffusion de documents scientifiques de niveau recherche, publiés ou non, émanant des établissements d'enseignement et de recherche français ou étrangers, des laboratoires publics ou privés. 


\section{Jellyfish degradation in a shallow coastal Mediterranean lagoon}

2

3

$4 \quad$ Raquel Marques ${ }^{1,2^{*}}$, Marta Rufino $^{3,4}$, Audrey M. Darnaude ${ }^{1}$, Frédérique Carcaillet ${ }^{1}$, Marie $5 \quad$ Meffre $^{1}$, Delphine Bonnet ${ }^{1}$

$6 \quad{ }^{1}$ MARBEC, Univ. Montpellier, CNRS, Ifremer, IRD, Montpellier, France

$7 \quad{ }^{2}$ German Center for Marine Biodiversity Research (DZMB), Senckenberg am Meer, Martin-Luther-

8 King Platz 3, D-20146 Hamburg, Germany

9 곤 Instituto Português do Mar e da Atmosfera (IPMA, I.P.), Divisão de Modelação e Gestão de Recursos 10 Pesqueiros, Av. Dr. Alfredo Magalhães Ramalho, 6, 1495-165 Lisboa

$11{ }^{4}$ Centro de Ciências do Mar (CCMAR), Universidade do Algarve, Campus de Gambelas, 8005-139 12 Faro, Portugal

*Corresponding author: raquel.marques@ umontpellier.fr / raquel.marques@ senckenberg.de / marques.rfs@gmail.com

Present address : ${ }^{2}$ German Center for Marine Biodiversity Research (DZMB), Senckenberg am Meer, Martin-Luther-King Platz 3, D-20146 Hamburg, Germany

Key words: Aurelia coerulea, Macrobenthic community, Thau lagoon, Sediment, Seagrass

Present address : ${ }^{2}$ German Center for Marine Biodiversity Research (DZMB), Senckenberg am Meer, Martin-Luther-King Platz 3, D-20146 Hamburg, Germany 
Recurrent jellyfish blooms in the coastal zone call for understanding the impacts of jelly-falls on the functioning of benthic communities, especially in shallow enclosed ecosystems where their biomass can affect local carbon cycling and productivity. Each year, blooms of the jellyfish Aurelia coerulea appear and collapse in a semi-enclosed coastal Mediterranean lagoon (the Thau lagoon, south of France). Although the lagoon is shallow, large accumulations of dead jellyfish are never observed on its bottom, so it was hypothesized that decaying jellyfish were rapidly consumed by local macrobenthic organisms. The current work aimed to test this hypothesis, by estimating the impact of the presence of dead $A$. aurelia medusae on local macrobenthic community composition and assessing their biomass loss rates under different scenarios of accessibility by the macrobenthos. Unexpectedly, our results revealed a limited role of macrobenthic scavengers in the disappearance of dead medusae, although this later was particularly fast (19 to 78h). Only one taxon (Tritia sp., Nassariidae family) showed a significant response to the presence of dead A. coerulea medusae on the seabed. Thus, our results suggest that the fast disappearance of dead jellyfish biomass in Thau results from its rapid degradation and consumption by local microorganisms, likely due to the combined effects of high local temperatures and the small size of A. coerulea medusae. Thus, the important biomass produced during A. aurelia blooms in Thau might essentially boost its microbial food web. The potential role of jellyfish blooms in controlling biogeochemical cycles and food web functioning in shallow lagoons is discussed, underlying the need to include this process in ecosystem-based models. 
Jellyfish (in particular scyphozoans) are famous for their conspicuous blooms, which may locally generate biomasses exceeding $10 \mathrm{t}$ wet weight $100 \mathrm{~m}^{-3}$ (Lilley et al. 2011). The population dynamics of jellyfish at the pelagic stage is frequently described as 'bloom and bust', since jellyfish blooms collapse rapidly, usually within a few weeks or months (Pitt et al. 2014). This might cause large accumulations of sinking dead jellyfish (referred to as jelly-falls) on the seafloor (Lebrato et al. 2012), which can be particularly impressive, especially in deep-sea habitats (Billett et al. 2006; Yamamoto et al. 2008; Lebrato and Jones 2009; Sweetman and Chapman 2011, 2015) where they can form localized layers of up to $70 \mathrm{~cm}$ in thickness $\left(78 \mathrm{~g} \mathrm{C} \mathrm{m}^{-2}\right)$ on the seabed (Billett et al. 2006). These massive accumulations of jelly-falls are likely sporadic and considered as anomalies when compared with the mean annual jellyfish fluxes in those regions (Luo et al. 2020). However, jellyfish are common worldwide and represent a global biomass of $290 \mathrm{Tg} C$ (Luo et al. 2020) with very high sinking speeds (Lebrato et al. 2013) which calls for a better understanding of the impacts of jelly-falls on the functioning and productivity of benthic communities.

When jellyfish blooms collapse, this accumulated organic matter has several possible fates. First, it can be consumed or fragmented by pelagic predators and scavengers (Cardona et al. 2012; Bos et al. 2017; Hays et al. 2018; Marques et al. 2019). Otherwise, carcasses sink through the water column (Lebrato et al. 2012) where they can be degraded by pelagic microbial communities (Titelman et al. 2006; Blanchet et al. 2015; Tinta et al. 2016, 2020). The amount of jellyfish biomass that reaches the seafloor depends, thus, on their decay rate, the sinking speed of the carcasses, the depth at which the jellyfish die, and the depth of the water column itself (Lebrato et al. 2011, 2019). Decay rates for jellyfish depend on the temperature (Lebrato et al 2011), while their sinking speed is a function of their size, diameter, bio-volume, geometry, density, and drag coefficients (Yamamoto et al. 2008; Lebrato et al. 2011, 2012, 2013). If not degraded in the water column (Titelman et al. 2006; Tinta et al. 2016, 2020), jelly-falls accumulate on the seabed, with potentially important impacts on both the biogeochemical cycling and the functioning of benthic 
characterized by protein-rich organic matter, low $\mathrm{C}: \mathrm{N}$ ratio, and no hard exoskeleton, being described as highly bioavailable for some particular microbial organisms with very high growth efficiency (Tinta et al. 2012, 2020). This may lead to high consumption of dissolved oxygen and a drastic decrease of its concentrations in the vicinity of jellyfish carcasses (West et al. 2009; Sweetman et al. 2016; Chelsky et al. 2016; Guy-Haim et al. 2020), which might induce inhospitable conditions for the benthic macrofauna, decreasing its activity, causing local emigrations or even massive mortalities (Sweetman et al. 2016; Chelsky et al. 2016). Nevertheless, dead jellyfish can also potentially provide suitable food for many benthic species, including fishes, echinoderms, anthozoans, polychaetes, gastropods, and crustaceans (Lebrato et al. 2012; Sweetman et al. 2014; Chelsky et al. 2016; Ates 2017). These later can consume considerable amounts of jelly-falls biomass within few hours, which considerably boosts benthic productivity (Sweetman et al. 2014). This scavenging behaviour plays a key role in benthic ecosystem functioning as it determines the fate of the organic matter that reaches the seafloor, i.e. whether the organic material from jelly-falls contributes to the microbial loop or enters the macrofaunal food web (Sweetman et al. 2014, 2016).

So far, the microbial degradation of jelly-falls has been relatively well described (Titelman et al. 2006; West et al. 2009; Tinta et al. 2010, 2012, 2020; Condon et al. 2011; Frost et al. 2012; Blanchet et al. 2015; Sweetman et al. 2016). However, studies investigating the impact of jellyfalls on benthic macrofaunal communities are still scarce (Sweetman et al. 2014; Chelsky et al. 2016; Dunlop et al. 2017). Such studies are imperative for coastal habitats, where the highest jellyfish biomass values were reported (Luo et al. 2020) and the anthropogenic impacts are intense and pointed out as likely promoters of jellyfish blooms (Purcell 2012). This is particularly evident in coastal lagoons, where jellyfish blooms occur regularly (e.g. Fuentes et al., 2011; Marques et al., 2015a), with abundances that can overcome 530 tonnes km ${ }^{-2}$ (Pitt and Kingsford 2003). These ecosystems are very productive enclosed systems, supporting important ecological processes and providing numerous ecosystem services (Newton et al. 2014; De Wit et al. 2017), but very little information is available regarding the fate of jelly-falls within these shallow environments (Chelsky et al. 2016). Despite the frequent occurrence of jellyfish blooms, to our knowledge, 
massive accumulations of jelly-falls on coastal lagoons' floor were never reported. Although

107 jellyfish can be rapidly degraded by pelagic microbial communities (Tinta et al. 2020), jelly-falls should still be observed on lagoons' seabed because, in such shallow habitats, sinking jellyfish are likely to reach the bottom even before they die (Lebrato et al. 2012). Therefore, the absence of dead jellyfish on the seabed in these environments suggest that jelly-falls are rapidly eaten by local benthic scavengers and/or decomposed by local microorganisms.

112 The current work aims to investigate this issue and evaluate the contribution of macrobenthic 113 scavengers in the disappearance of jellyfish biomass in coastal lagoons. To this aim, we studied 114 the fate of dead medusae of the jellyfish Aurelia coreulea when ending on the seafloor in a shallow lagoon located in the south of France: the Thau lagoon. In situ experiments were carried out by adding dead medusae on the seabed of the lagoon under different scenarios of accessibility by macrobenthic scavengers. The experiments were performed in two contrasting types of habitat, typical of this shallow ecosystem, assuming that the different macrobenthic community composition associated with each habitat would have a different impact on the biomass loss rate of the jelly-falls. In particular, we tested whether if the addition of dead jellyfish on the seabed scavengers (Chelsky et al. 2016). depth, and is highly influenced by strong wind events (Fiandrino et al. 2012). The local tidal range is weak $(<1 \mathrm{~m})$, which promotes a high water residence time $(1-4$ months, Fiandrino et al., 2012). With regards to jellyfish, the Thau lagoon has the particularity to harbour its own population of Aurelia coerulea, isolated from those in the Mediterranean Sea (Bonnet et al. 2012; Marques et al. 2015b) which offers a rare occasion to study the fate of the blooms of this species. In the lagoon, A. coerulea ephyrae first appear in the early winter (November - December), to 
134 give rise to medusae at the beginning of spring (April - May), when temperature increases

135 (Marques et al. 2015a). High abundances of medusae, associated with high growth rates generate

136 the annual jellyfish bloom, which usually collapses in the early summer (June-July). Although

137 sparse decaying medusae are regularly seen on the lagoon floor, either on bare sediment or

138 entangled in seagrass leaves (R. Marques, personal observation), large accumulations of $A$.

139 coerulea carcasses have never been observed so far.

140 To try to elucidate the local fate of $A$. coerulea jelly-falls, two different in situ experiments were

141 performed: one (1) to assess medusae biomass loss rates under different scenarios of medusae

142 accessibility for benthic scavengers, and one (2) to study the impact of jellyfish presence on the

143 seafloor on the composition of local macro-benthic communities (Fig. 1). Both experiments were

144 performed in a shallow area $(<1 \mathrm{~m}$ depth), where dead jellyfish had already been observed on the

145 seabed and repeated in the two most common habitats found in the lagoon (Plus et al. 2003): on

146 bare sediments and in seagrass (Zostera noltii) meadows.

147 This study was conducted in 2018 , during the collapse of the annual bloom of A. coerulea. Due

148 to logistic constraints, the two experiments were performed on different days (on May $30^{\text {th }}$ and

149 June $07^{\text {th }}, 2018$ ). However, all the medusae used were collected alive on the same day (May $28^{\text {th }}$,

150 2018). This was done using hand nets to avoid damaging the medusae and they were immediately

151 transported to the laboratory in ambient seawater. All medusae were then kept alive for 2 to 10

152 days, in $1 \mathrm{~m}^{3}$ tanks (ca. 100 ind. $\mathrm{m}^{-3}$ ) with open seawater circulation system (i.e. seawater from

153 the lagoon) to ensure similar rearing conditions as in situ. They were all fed once per day with

154 newly hatched Artemia to ensure their survival. A few hours before each experiment, live, healthy

155 and active medusae were selected from the husbandry tanks and equally distributed in $30 \mathrm{~L}$ cold

156 boxes, filled with ambient seawater. Medusae were killed by sparging the water with nitrogen gas

157 for ca. 3h following Chelsky et al. (2016). The medusae were then immediately transported (20

$158 \mathrm{~min})$ to the experimental site and placed in the experimental bags. 
a
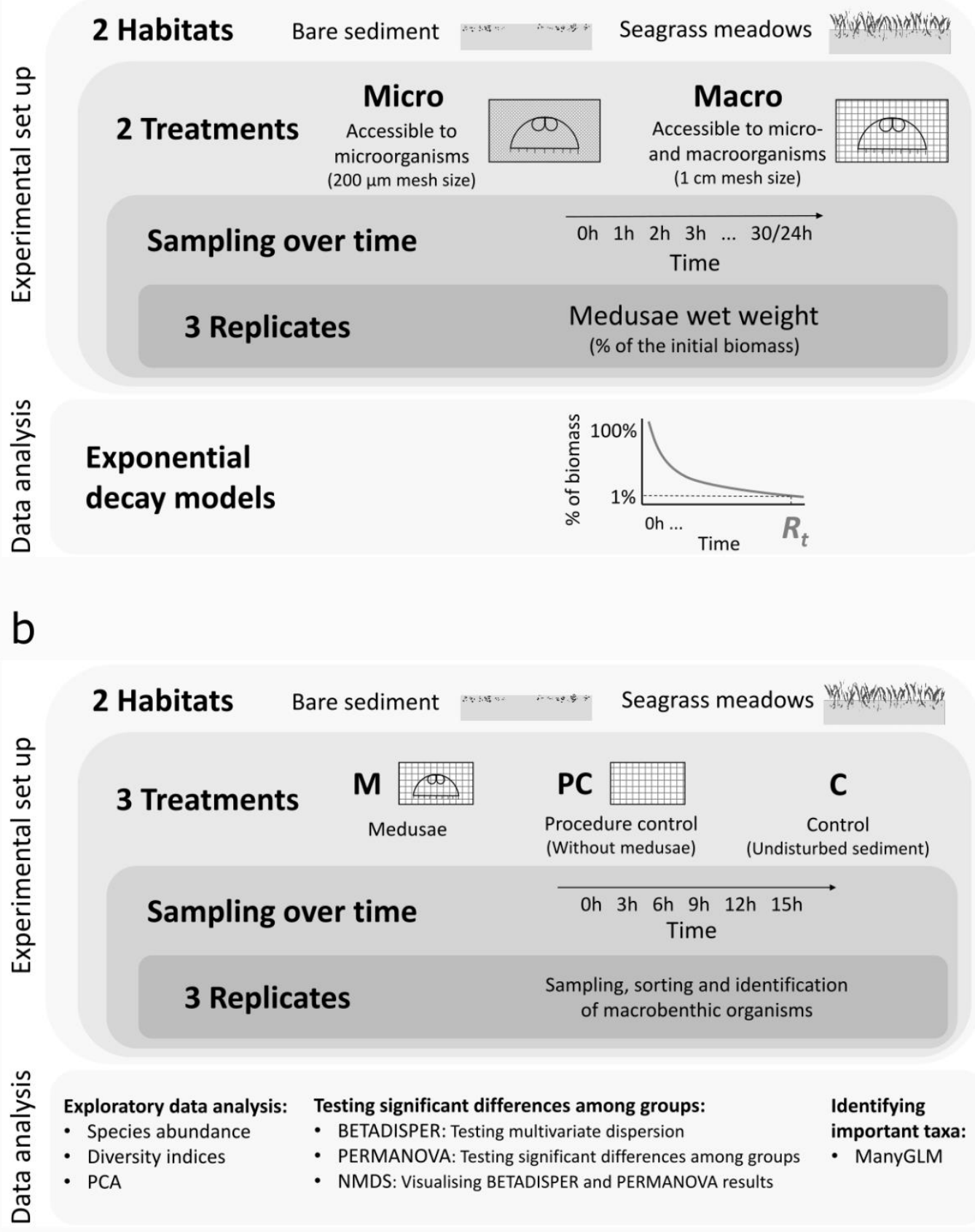

161 Fig. 1: Schematic representation of the two in situ experiments performed in this study: a) assessing jellyfish biomass 162 loss rates under different scenarios of medusae accessibility for benthic scavengers; $b$ ) assessing the impact of jellyfish degradation on the macrobenthic community composition.

\subsection{Jellyfish biomass loss rates}

\subsubsection{Experimental set-up}

167 Jellyfish biomass loss rates were assessed both on the bare sediment and seagrass meadows

168 habitats under two different scenarios of accessibility to dead medusae for the macrobenthic organisms of the lagoon (Fig.1a). 
The first scenario (Micro) involved placing individual medusae in $20 \times 15 \mathrm{~cm}$ net bags with a mesh size of $200 \mu \mathrm{m}$ so they were accessible only to microorganisms (e.g. bacteria, microzooplankton, and small mesozooplankton species). In the second scenario (Macro), medusae were placed in $20 \times 15 \mathrm{~cm}$ net bags with a mesh size of $1 \mathrm{~cm}$, which allowed both microorganisms and macroorganisms (e.g. gastropods, amphipods, crustaceans) to access them. In both scenarios, the net bags containing the dead medusae were protected with a $1.50 \times 2.00 \times$ $0.15 \mathrm{~m}$ net cage with a coarse mesh size of $2.5 \mathrm{~cm}$, to prevent medusae consumption by large organisms (e.g. large fish, echinoderms, crustaceans). However, the Macro scenario was also replicated without the protection net cage to assess if medusae consumption by large scavengers was significant. Since no significant effect of the cage could be evidenced (generalised nonlinear least square model, $\mathrm{p}$-value $=0.17$ and 0.62 for bare sediment and seagrass habitats, respectively), data from Macro scenarios with and without cage were pooled.

Before each experiment, dead medusae were partially dried on a paper towel to absorb the excess water and mucus from their surface, weighted (wet weight in $\mathrm{g}$, to the nearest $0.1 \mathrm{~g}$ ), measured (bell diameter in $\mathrm{cm}$ ), and placed individually in a bag. In each scenario, 24 bags were fixed on the sediment using tent pegs, with a minimum distance of $1.5 \mathrm{~m}$ between them. For each of the two scenarios (Micro and Macro) and irrespective of the habitat (bare sediment or seagrass meadow), three replicates of individual medusa were collected at regular time intervals: every $1 \mathrm{~h}$ at the beginning of the experiment (when medusae degradation is usually faster, Titelman et al., 2006), and every 2 to $5 \mathrm{~h}$ afterwards, adjusted in each habitat type to ensure all the medusae biomass had disappeared from the net bags by the end of the experiment. The total experimental time was, therefore, different between habitats $(24 \mathrm{~h}$ and $30 \mathrm{~h}$ for the seagrass meadows and the bare sediment habitats, respectively). At each sampling time, collected bags were immediately placed inside a hermetic plastic bag to avoid the loss of biological material. The remaining medusa biomass within each bag was partially dried on a paper towel to absorb the excess water (when possible) and weighed to the nearest $0.1 \mathrm{~g}$ (wet weight). In situ temperature was measured (EC 300 VWR international/ WTW model 350i) right before the start and end of each experiment to detect differences in temperature between habitats. 
199 For each habitat (bare sediment and seagrass meadow) and accessibility scenarios (Micro and Macro), jellyfish biomass loss rates were determined by fitting exponential decay models to the non-averaged wet weights of medusae (percentage of the initial biomass) as a function of time:

$$
M_{t}=M_{0} e^{-\lambda t}
$$

where $M_{t}$ is the percentage of medusa biomass at time $t$ (in hours), $M_{0}$ and $\lambda$ are the model coefficients representing the initial $(t=0)$ medusa biomass (in percentage) and the loss rate, respectively. The biomass loss rates were then used to calculate the degradation time ( $D_{t}$ in hours), i.e. the time required to achieve a loss of 50\% $(t=0.5)$ and $99 \%(t=0.01)$ of the initial biomass of medusa, according to the following equation (Lebrato et al. 2011):

$$
D_{t}=\frac{-\ln (t)}{\lambda}
$$

Differences, according to the accessibility scenarios and the habitats, were tested by fitting generalised nonlinear least square models (GNLS) using "nlme" package (Pinheiro et al. 2019), which allows fitting the model to zero values, using 100 and 0.01 as starting parameters, for $M_{0}$ and $\lambda$, respectively.

Significant differences in the initial medusae biomass and environmental conditions (temperature) between habitats and treatments were assessed by Kruskal-Wallis and T-tests, after verifying the normality assumptions.

\subsection{Impact on macrobenthic community composition}

To test the impact of dead jellyfish presence on benthic community composition, a second experiment was carried out on both habitats.

The experiments started $\left(\mathrm{t}_{0}\right)$ at $16 \mathrm{~h} 30$ and $15 \mathrm{~h} 40$ on the seagrass meadows and the bare sediment, respectively, and samples were collected at five sampling times (every $3 \mathrm{~h}$ ) for $15 \mathrm{~h}$ (Fig. 1b), based on the preliminary results of the jellyfish biomass loss rates experiments. In each habitat, three different treatments were performed. The medusa (M) treatment was a replication of the Macro 
scenario from the previous experiment: one dead medusa was placed within a $1 \mathrm{~cm}$ mesh net bag,

226 thereby being accessible to both micro- and macroorganisms. The procedure control (PC)

227 treatment aimed to test the effect of the experimental setup and therefore the M treatment was

228 reproduced without any medusa in the net bag. The last treatment was for control (C). In this case,

229 the sampling was performed on undisturbed areas of each habitat. To assess differences in

230 macrobenthic community composition between treatments, the substrate (sediment and seagrass)

231 below each bag was collected, as well as the organisms present on its surface and top of the bags.

232 This sampling was performed immediately upon medusae (in M) or empty bag (in PC) collection.

233 Three replicates were collected per combination of habitat, treatment, and sampling time. In each

234 case, the sediment was sampled using a shovel $\left(0.03 \mathrm{~m}^{2}, 4 \mathrm{~cm}\right.$ deep $)$ and placed inside a hermetic

235 plastic bag, ensuring a minimum sample loss. Samples were stored in cold boxes and frozen

236 within $6 \mathrm{~h}$, until later laboratory analysis. In situ temperature was measured (EC 300 VWR

237 international/ WTW model 350i) before the start of the experiment and at each sampling time to

238 detect differences in temperature between habitats.

239 Once in the laboratory, the volume of sediment in each sample was measured using a graduated

240 beaker to standardize the abundance of organisms by sampling area $\left(\mathrm{m}^{2}\right)$. The sediment was

241 sieved (1 mm mesh size) and its macrofauna was sorted, counted, and identified under a dissecting

242 microscope according to D'Angelo and Gargiullo (1978), Fauvel (1927), and Fauvel (1923). The

243 organisms were identified to the lowest taxonomic level. However, since identification at the

244 species level was not possible for all organisms, species of the same genus were grouped.

245 Annelids and Decapods were identified down to the family level only.

2.3.2.Data analysis

248 Only taxa representing more than $1 \%$ of the total community biomass in each habitat were considered for data analysis, to reduce the influence of rare organisms. Diversity indices (Shannon

250 and Pielou's evenness indices) were calculated using the "BiodiversityR" package (Kindt and 251 Coe 2005), based on "vegan" package in R (Oksanen et al. 2019). The changes in total abundance 252 (after logarithmic transformation) and diversity indices, among habitats, scenarios, and sampling 
times were tested using linear models. For each variable (i.e. total abundance, Shannon, and

254 Pielou's evenness indices) a full model was produced, with all main terms and respective interactions (index $\sim$ habitat $*$ treatment $*$ sampling time). Model selection was then carried out using the Akaike information criterion (AIC), following Zuur et al. (2009). Visual inspection of residual plots did not reveal any obvious deviations from homoscedasticity or normality. Differences between each combination of treatment and sampling time within each habitat were tested using post hoc Tukey HSD tests for multiple comparisons.

260 Changes in community composition among habitats, treatment, and sampling time were analysed using three different complementary approaches. First, the community composition was represented through a principal component analysis (PCA) of the abundances $(\log (x+1))$.

Second, differences between community composition among habitats, treatments, and sampling times were assessed through a permutational multivariate analysis of variance (PERMANOVA, with 9999 permutations), using Bray-Curtis distance. Since homogeneity of dispersion between factors is an assumption of the PERMANOVA analysis, multivariate dispersion was first tested using BETADISPER. When significant differences were observed, a pairwise comparison was performed (PERMUTEST, with 9999 permutations). Nonmetric Multidimensional Scaling (NMDS) plots were used to visualize the results of BETADISPER and PERMANOVA, as recommended (Anderson 2017). These analyses were performed using the package "vegan" (Oksanen et al. 2019).

Third, to cope with the limitations reported for PERMANOVA, which does not take into consideration the influence of the mean-variance structure of each species (Warton et al. 2012), we also ran a model-based approach using a multi-taxa generalized linear model (ManyGLM, "manyglm" function, from package "mvabund"; Wang et al., 2012). A two fixed factor model structure (sampling time and treatment) was used, separately for each habitat, with a negative binomial distribution and a log-link function. The examination of residual plots of the model showed the absence of a clear pattern, validating the model. This analysis was also used to determine which species contributed most to the differences observed. 


\section{Results}

The initial wet weights of the A. coerulea medusae used in the experiments (Table 1) were similar among scenarios within each habitat (Kruskal-Wallis, $\chi^{2}=0.32, \mathrm{df}=1$, p-value $=0.57$ and $\chi^{2}=$ $0.61, \mathrm{df}=1, \mathrm{p}$-value $=0.44$ for bare sediment and seagrass, respectively), but differed between habitats (Kruskal-Wallis, $\chi^{2}=81.33$, $\mathrm{df}=1$, $\mathrm{p}$-value $<0.001$ ). Indeed, as the experiments started on different days for the two habitats and medusae were kept alive between the two experiments, differences in the time spent in captivity likely induced a bias on the initial weight of the medusae. The initial and final experimental temperatures were similar for the two habitats $\left(23.5 \pm 0.7^{\circ} \mathrm{C}\right.$ and $23.4 \pm 0.5^{\circ} \mathrm{C}$ on the seagrass meadows and bare sediment, respectively; T-test, $\mathrm{p}$-value $=$ $0.8)$, suggesting a limited effect of temperature on the results.

The disappearance of A. coerulea biomass was fast irrespective of the scenario or habitat (Fig. 2), with $\lambda$ coefficient ranging from -0.24 to -0.06 per hour (i.e. -1.42 to -5.8 per day, Table 1 ). All model fits and correspondent coefficients were statistically significant (GNLS, p-value $<0.001$, Table 2). On the bare sediment habitat, the jellyfish biomass loss rate was not affected by the accessibility scenarios (GNLS, p-value $=0.798$ ), while on the seagrass meadow the biomass loss rate was significantly higher (GNLS, p-value $<0.001)$ in the Micro scenario than in the Macro one. Irrespective of the scenario, medusae degradation was significantly faster on the bare sediments (GNLS, p-value < 0.001), where $99 \%$ of the initial medusae biomass was lost in about 19 hours in both accessibility scenarios (Table 1). Medusae biomass loss was slower on seagrass meadows: under the Macro scenario, $R t$ was estimated at $78 \mathrm{~h}$, while microorganisms alone degraded $99 \%$ of the biomass in $32 \mathrm{~h}$. However, medusae biomass loss was consistently faster during the first few hours of the experiments, with a $50 \%$ loss of the initial biomass in $3 \mathrm{~h}$ on bare sediment (both scenarios), against 5 and $12 \mathrm{~h}$ on seagrass meadows, for Micro and Macro scenarios, respectively.

Table 1: Mean initial wet weights (W) and bell diameters (BD) of the dead A. coerulea medusae used in each experiment and resulting estimates of biomass loss rate ( $\lambda$ in hours) and degradation time (Dt in hours).

\begin{tabular}{lllll}
\hline Scenario & Initial W $(\mathbf{g} \pm$ SD) & Initial BD $(\mathbf{c m} \pm$ SD $)$ & $\lambda(\mathbf{h})$ & Dt (h) \\
\hline
\end{tabular}




\begin{tabular}{lcccc}
\hline & \multicolumn{4}{c}{ Bare sediment } \\
\cline { 2 - 5 } Macro & $34.8 \pm 12.4$ & $8.0 \pm 1.3$ & -0.24 & 19.51 \\
Micro & $32.8 \pm 14.9$ & $8.1 \pm 1.5$ & -0.24 & 19.05 \\
\hline & \multicolumn{5}{c}{ Seagrass meadows } \\
Macro & $107.5 \pm 20.0$ & $12.8 \pm 0.9$ & -0.06 & 78.04 \\
Micro & $111.8 \pm 19.0$ & $13.2 \pm 1.0$ & -0.15 & 31.56 \\
\hline
\end{tabular}

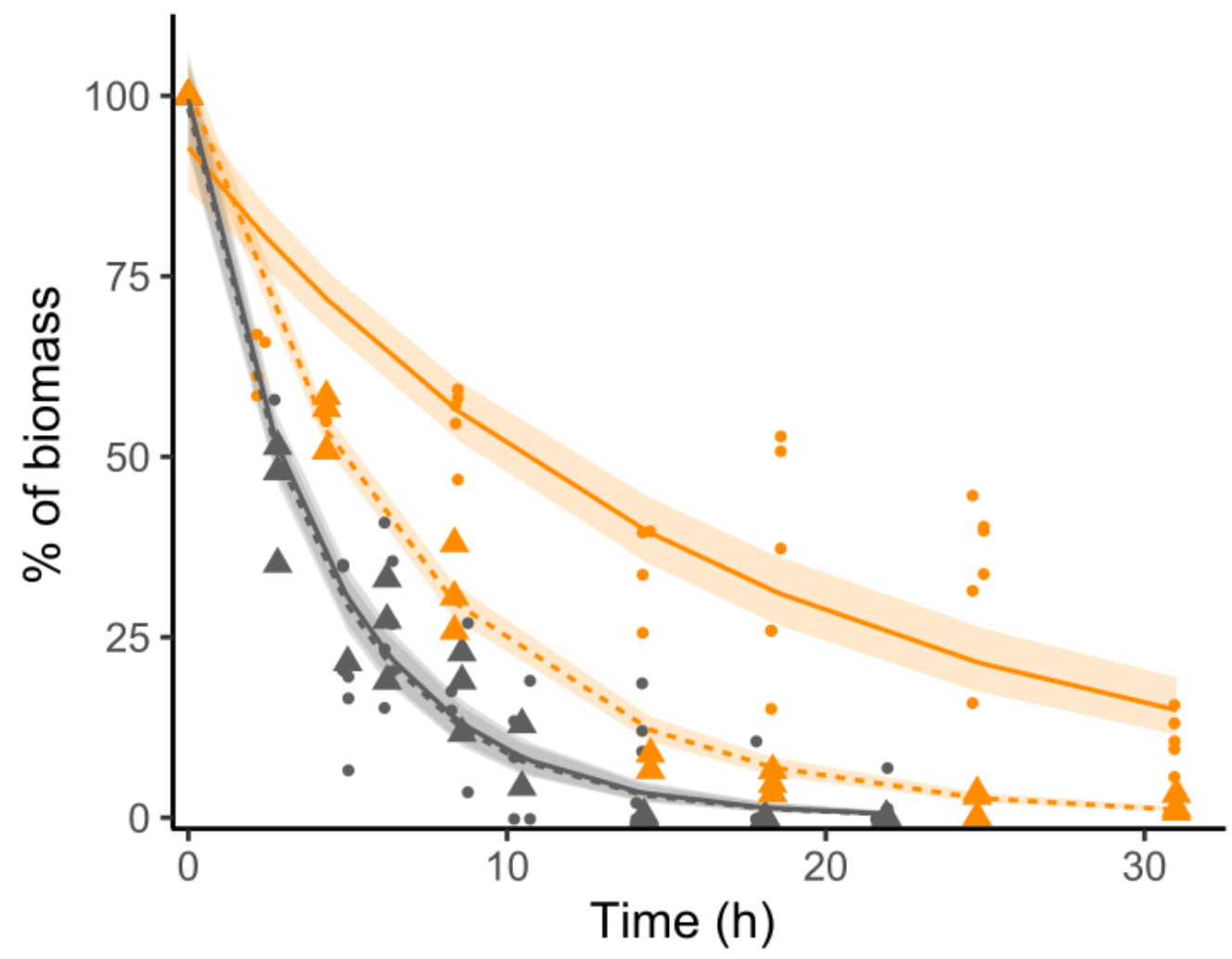

\section{$\rightarrow$ Macro - - Micro $\bullet$ Seagrass meadows $\bullet$ Bare sediment}

311

312

313

314

315

316

317

Fig. 2: Dynamic of A. coerulea medusae biomass loss in both habitats (bare sediment and seagrass meadows) under both accessibility scenarios (Macro and Micro). Exponential decay models (lines) were fitted to the non-averaged data of biomass (in $\%$ of the initial medusae biomass), with $95 \%$ confidence intervals (shadow areas).

Table 2: Estimation of the parameters (M0 and $\lambda$ ) by the GNLS models used to assess differences between scenarios within each habitat. Significant differences $(p$-value $<0.05)$ are indicated in bold.

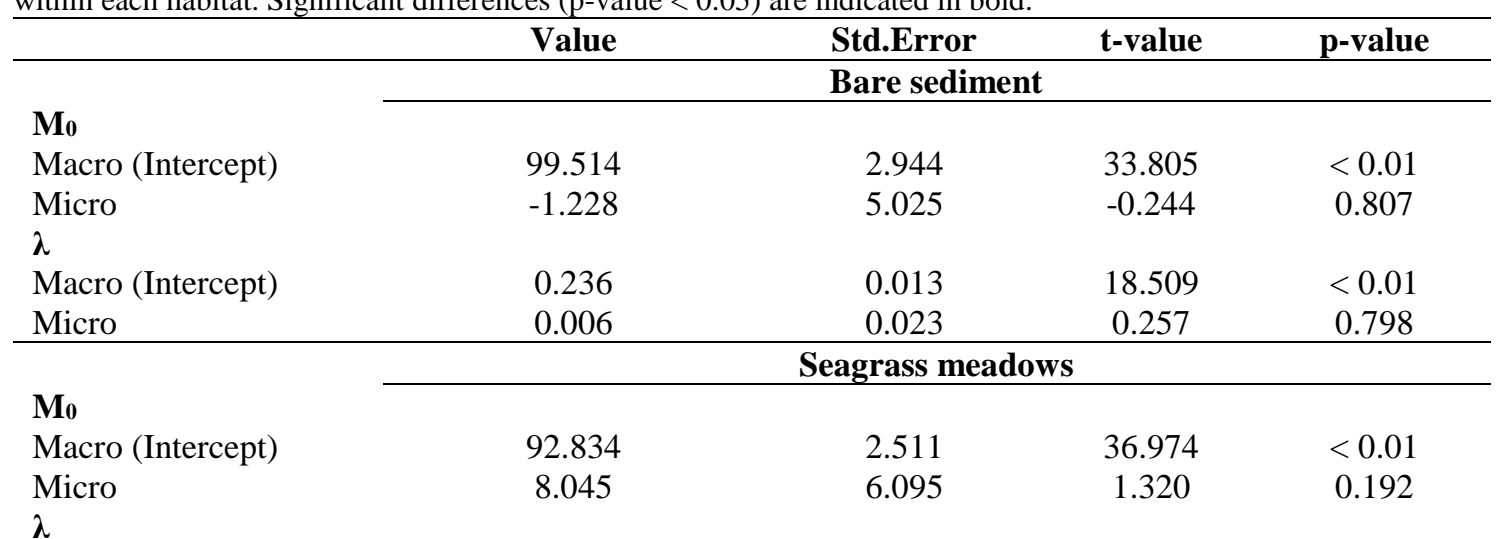




\begin{tabular}{|c|c|c|c|c|}
\hline Macro (Intercept) & 0.059 & 0.004 & 14.525 & $<0.01$ \\
\hline Micro & 0.087 & 0.017 & 5.142 & $<0.01$ \\
\hline
\end{tabular}

3.2.1.General composition of macrobenthic communities

322 A total of 9478 macrobenthic organisms, belonging to 34 different taxa, were identified during

323 the study. The two types of habitats investigated differed in terms of species richness with a higher

324 average number of taxa on seagrass meadows (29) than on bare sediments (20). However,

325 macrobenthic communities on seagrass meadows were clearly dominated by nine taxa only (Fig.

326 3). On this type of habitat, the gastropods Bittium sp. and the bivalves Ruditapes sp. represented together more than $80 \%$ of the total abundance recorded in all treatments: Medusae (M, 67.8 and

$32817.4 \%$, respectively), Procedure Control (PC, 58.5 and 25.4\%, respectively) and Control (C, 41.6

329 and $41.3 \%$, respectively). On bare sediments, macrobenthic communities were more balanced: in

330 the $\mathrm{C}$ treatment, $81.7 \%$ of the total abundance was represented by the annelid Glyceridae (28.2\%),

331 and the gastropods Bittium sp. (23.6\%), Tricolia sp. (17.9\%), and Rissoa sp. (12.1\%); in the M 332 treatment, the contribution of Glyceridae dropped to $12.5 \%$, while taxa like Ruditapes sp. and 333 Tritia sp. increased their importance representing $15.8 \%$ and $8.9 \%$ of total abundance, 334 respectively; and in the PC treatment the most abundant taxa were Bittium sp. (24.4\%), Tricolia sp. (16.5\%), Rissoa sp. (15.4\%) and Glyceridae (12.2\%). 

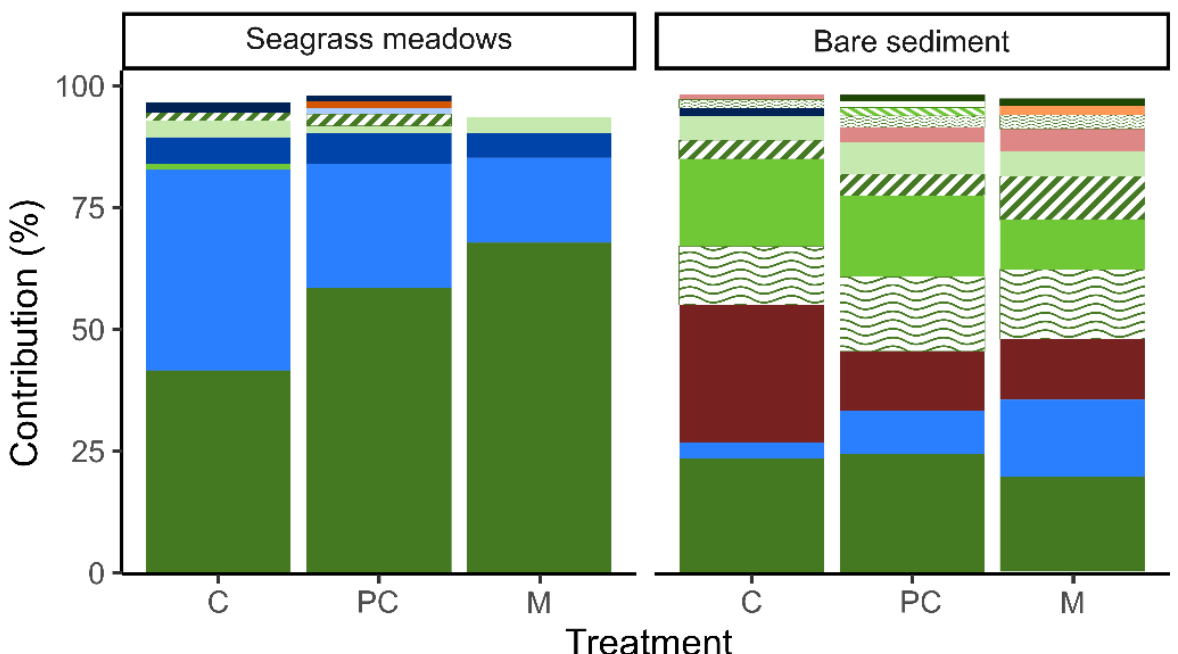

\begin{tabular}{ll}
\multicolumn{2}{c}{ Gastropoda } \\
\hline Bittium sp. (B) & Hexaplex sp. (H) \\
Tricolia sp. (Tri) & Jujubinus sp. (Ju) \\
Gibbula sp. (Gi) & Cerithium sp. (C) \\
Tritia sp. (T) & Gastropoda \\
E. Rissoa sp. (R) & Non identified (GNI)
\end{tabular}

\begin{tabular}{l} 
Bivalvia \\
\hline Cerastoderma sp. (Ce) \\
Loripes sp. $(\mathrm{L})$ \\
Ruditapes sp. $(\mathrm{Ru})$ \\
Gastrana sp. $(\mathrm{Ga})$
\end{tabular}

\begin{tabular}{c} 
Annelida \\
\hline Glyceridae (GI) \\
Cirratulidae (Ci) \\
Crustacea \\
\hline Sphaeroma sp. (S) \\
Microdeutopus sp. (M)
\end{tabular}

Fig. 3: Contribution of the most important taxa to the total abundance of the community on the seagrass meadows and bare sediment, in each treatment (M: Medusae, C: Control, PC: Procedure control). Only species that contributed to more than $1 \%$ of the total abundance are presented.

\subsubsection{Abundance and diversity indices}

The abundance of macrobenthic organisms was, on average, 10 times higher ( $\mathrm{p}$-value $<0.001$, Fig.4A and B, Table 3$)$ on the seagrass meadows than on the bare sediments $(6800 \pm 8830$ and $637 \pm 717$ ind. $\mathrm{m}^{-2}$, respectively). It was significantly affected by all factors considered (habitat, sampling time, and treatment, Table 3), but the overall interaction among these factors was not significant, indicating that treatment and time similarly affected the abundance of organisms within each habitat. Differences in total macrobenthic abundance among treatments were only observed at $3 \mathrm{~h}$ on the seagrass meadows, and 3 and $9 \mathrm{~h}$ on the bare sediments (Tukey HSD, pvalue < 0.05; Fig. 4A and B). This was particularly evident at 3h, when a peak of macrobenthos abundance was detected for both M and PC (both over 1500 ind. $\mathrm{m}^{-2}$ and 190 ind. $\mathrm{m}^{-2}$, on seagrass meadows and bare sediment, respectively), with significantly higher values than in C (Tukey HSD, p-value < 0.05). However, no differences in abundance were observed between M and PC (Tukey HSD, p-value > 0.05) over the whole experiment time. In both habitats, the abundance of macrobenthic organisms in the controls did not vary significantly over time (Tukey HSD, p-value 

$>0.05$ ), except at $12 \mathrm{~h}$ in the seagrass habitat, when it was significantly lower than at $\mathrm{t}_{0}$ (Tukey HSD, p-value $=0.02)($ Fig. 4A and B).

357 The diversity of macrobenthic organisms (Shannon diversity index) appeared to vary differently 358 depending on the habitat (Fig. 4C and D, Table 3). In seagrass meadows, it increased significantly 359 at the end of the study period $(9,12$, and $15 \mathrm{~h}$; Tukey HSD, p-value $<0.05$; Fig. 4C), but did not 360 vary among treatments while, on bare sediments, differences were only observed among 361 treatments, with higher diversities in $\mathrm{M}$ and PC than in $\mathrm{C}$ at $3 \mathrm{~h}$ (Tukey HSD, p-value $=0.01$; Fig. $3624 \mathrm{D})$.

363 For Pielou's evenness index, only the sampling time and habitat factors were retained in the linear 364 model (Table 3), showing that the treatment did not affect community evenness. Differences in the evenness were only observed on the seagrass meadows, where it was lower at $3 \mathrm{~h}$, suggesting a possible disturbance of the community (Tukey HSD, p-value < 0.05; Fig. 4E and F).

Table 3: Results of the linear models and the effect of each factor (Habitat, Time, and Treatment), on each variable (Abundance, Shannon, and Evenness diversity indices). Bold values indicate significant differences between at least two groups, at $\alpha=0.05$.

\begin{tabular}{|c|c|c|c|c|c|}
\hline Abundance & Df & Sum Sq & Mean Sq & F value & $\operatorname{Pr}(>\mathbf{F})$ \\
\hline Time & 5 & 18.294 & 3.659 & 8.687 & $<0.001$ \\
\hline Treatment & 2 & 24.407 & 12.204 & 28.974 & $<0.001$ \\
\hline Habitat & 1 & 156.490 & 156.490 & 371.541 & $<0.001$ \\
\hline Time:Treatment & 8 & 19.163 & 2.395 & 5.687 & $<0.001$ \\
\hline Time:Habitat & 5 & 8.792 & 1.758 & 4.175 & 0.002 \\
\hline Treatment:Habitat & 2 & 4.745 & 2.372 & 5.633 & 0.006 \\
\hline Time:Treatment:Habitat & 8 & 6.233 & 0.779 & 1.850 & 0.084 \\
\hline \multicolumn{6}{|l|}{ Shannon } \\
\hline Time & 5 & 1.304 & 0.261 & 1.853 & 0.115 \\
\hline Treatment & 2 & 2.986 & 1.493 & 10.610 & $<0.001$ \\
\hline Habitat & 1 & 2.528 & 2.528 & 17.962 & $<0.001$ \\
\hline Time:Treatment & 8 & 2.195 & 0.274 & 1.949 & 0.068 \\
\hline Time:Habitat & 5 & 3.180 & 0.636 & 4.519 & 0.001 \\
\hline Treatment:Habitat & 2 & 2.612 & 1.306 & 9.281 & $<0.001$ \\
\hline Time:Treatment:Habitat & 8 & 2.176 & 0.272 & 1.933 & 0.070 \\
\hline \multicolumn{6}{|l|}{ Evenness } \\
\hline Time & 5 & 0.201 & 0.040 & 6.956 & $<0.001$ \\
\hline Habitat & 1 & 2.332 & 2.332 & 403.462 & $<0.001$ \\
\hline Time:Habitat & 5 & 0.085 & 0.017 & 2.936 & 0.017 \\
\hline
\end{tabular}



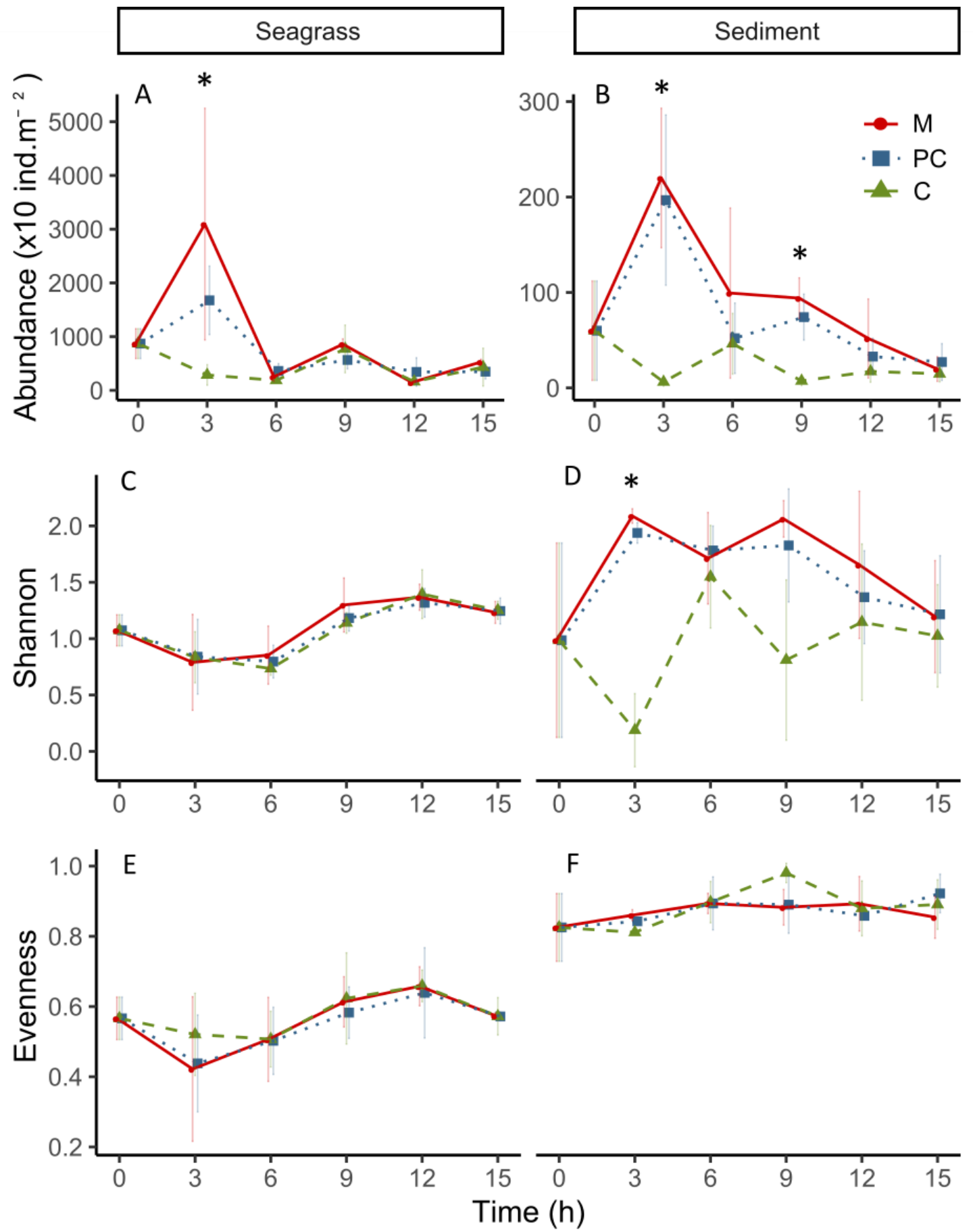

Fig. 4: Abundance of macrobenthic organisms (A and B, note the different scales for the two habitats), Shannon diversity index (C and $\mathrm{D})$, and Pielou's equitability index (Evenness) on the seagrass meadow (A, $\mathrm{C}$, and $\mathrm{E})$ and bare sediment $(\mathrm{B}, \mathrm{D}$, and $\mathrm{F})$ habitats. For each variable, dots represent average values and vertical bars standard deviations for each treatment (M: medusae, PC: procedure control, C: control). Asterisks indicate significant differences between treatments at $\alpha=0.05$.

\subsubsection{Differences in the community composition}

380 In the principal component analysis (PCA), only the first two axes (PC1 and PC2, Fig. 5) were retained since they represent the majority of the variability of the data $(69.7 \%)$. These axes 
driver of the variation in macrobenthic community composition observed between samples. In

seagrass meadows, the community was characterized by high abundances of Bittium sp. (B),

Ruditapes sp. (Ru), and Loripes sp. (L), whereas on the bare sediment Glyceridae (Gl), Rissoa sp.

(R), and Tricolia sp. (Tri) highly contributed to differentiate these groups. The effect of the samples (10) were collected at 3h (Fig. 5C) and only 3 were C samples (Fig. 5B).
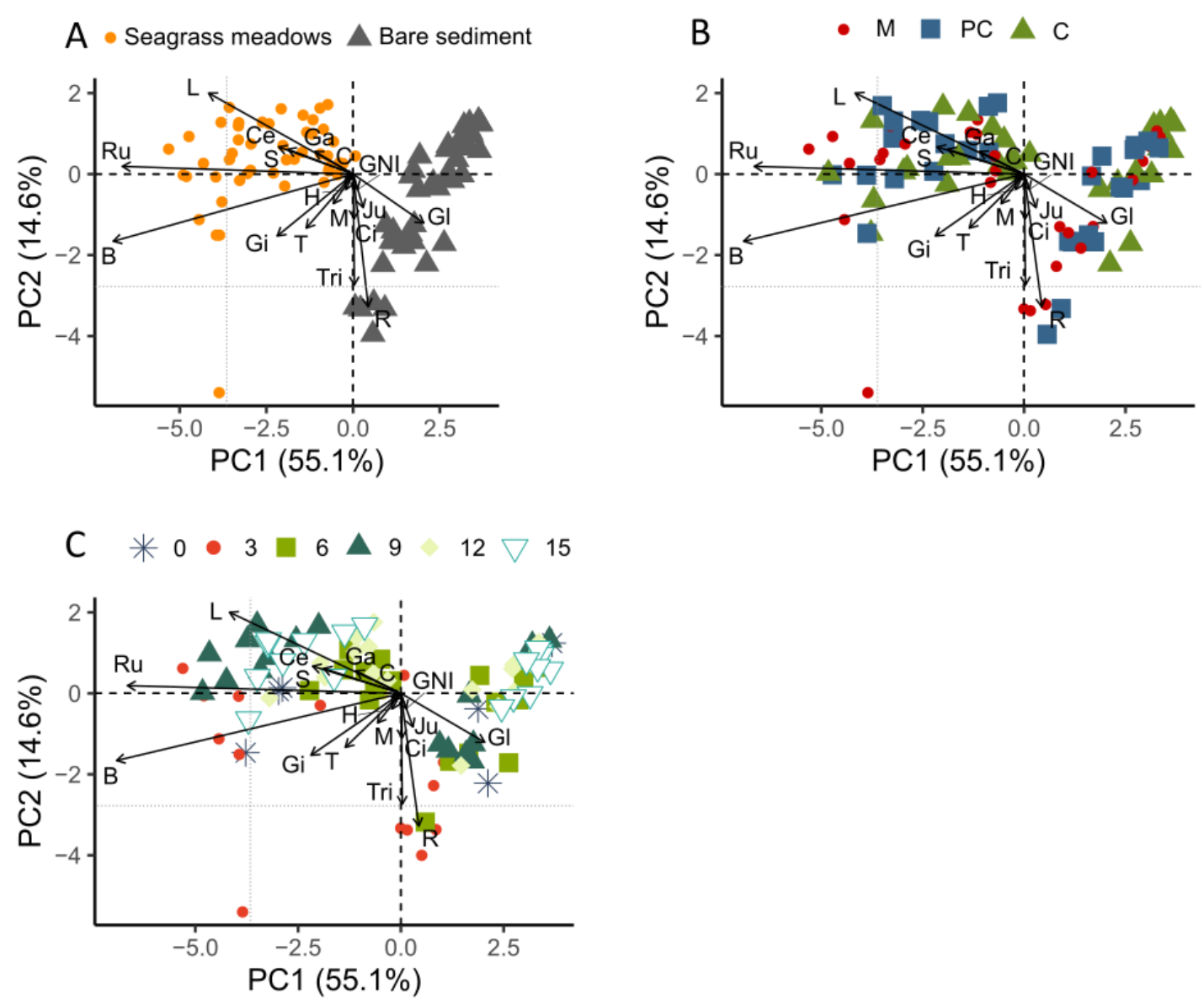

Fig. 5: Biplots of Principal Component Analysis (PCA). Samples (points) and taxa (arrows) are presented. In A, B, and $\mathrm{C}$, samples are identified according to habitat, treatment (M: medusae, PC: procedure control, $\mathrm{C}$ : control), and sampling time (in h), respectively. Grey dotted lines are indicative thresholds to identify the samples with high Euclidean distance from the centre. For the sake of simplicity, taxa names are abbreviated (see Fig. 3 with taxa codes).

The results from BETADISPER did not detect significant changes in community dispersion over time $(\mathrm{F}=0.7, \mathrm{p}=0.6)$ or among treatments $(\mathrm{F}=2.5, \mathrm{p}=0.08)$. However, the community dispersion 
was different between the two habitats $(\mathrm{F}=13.2$, $\mathrm{p}$-value $<0.001)$, and, therefore, BETADISPER

400 and PERMANOVA were performed for each habitat separately.

401 On the seagrass meadows, community dispersion was homogeneous among treatments $(\mathrm{F}=0.5$, p-value $=0.6$, Fig. 6A), but not across sampling time $(F=2.5$, p-value $=0.045$, Fig. 6B $)$. Pairwise comparisons identified the samples collected at $3 \mathrm{~h}$ as being different from those collected from 6 to $15 \mathrm{~h}$ ( $\mathrm{p}$-value $<0.05)$. The analysis was, therefore, repeated without the samples collected at $3 \mathrm{~h}$, to ensure homogeneity of dispersion among samples $(\mathrm{F}=0.3$, p-value $=0.9)$. Accordingly, a PERMANOVA was performed to determine changes in the community for the seagrass meadow, between treatments, sampling times, and the respective interaction (full model), omitting the samples collected at $3 \mathrm{~h}$. The results indicate that the community composition did not vary between treatments $(F=0.6, p$-value $=0.8$, Fig. $6 \mathrm{~A})$, but showed significant differences over time $(\mathrm{F}=9.3$, p-value $<0.01$, Fig. 6B).

411 In the bare sediment habitat, community dispersion was homogeneous across sampling times and 412 among treatments $(F=0.6$, p-value $=0.7$ and $F=0.4$, p-value $=0.7$, respectively, Fig. $6 \mathrm{C}$ and $\mathrm{D})$. 413 Therefore, a full factorial model of PERMANOVA (i.e. treatment, sampling time, and interaction) 414 was performed for this habitat. The results show that both factors significantly affected 415 macrobenthic community composition $(\mathrm{F}=2.8$, $\mathrm{p}$-value $<0.01$ and $\mathrm{F}=4.8$ and $\mathrm{p}$-value $<0.01$, respectively), with $\mathrm{PC}$ and $\mathrm{M}$ presenting similar values, whereas treatment $\mathrm{C}$ was significantly

417 different (Fig. 6C). However, the interaction between both factors was not significant $(\mathrm{F}=1.4$ 418 and $\mathrm{p}$-value $=0.09)$ indicating that changes in community composition among treatments were 419 not affected by sampling time. 

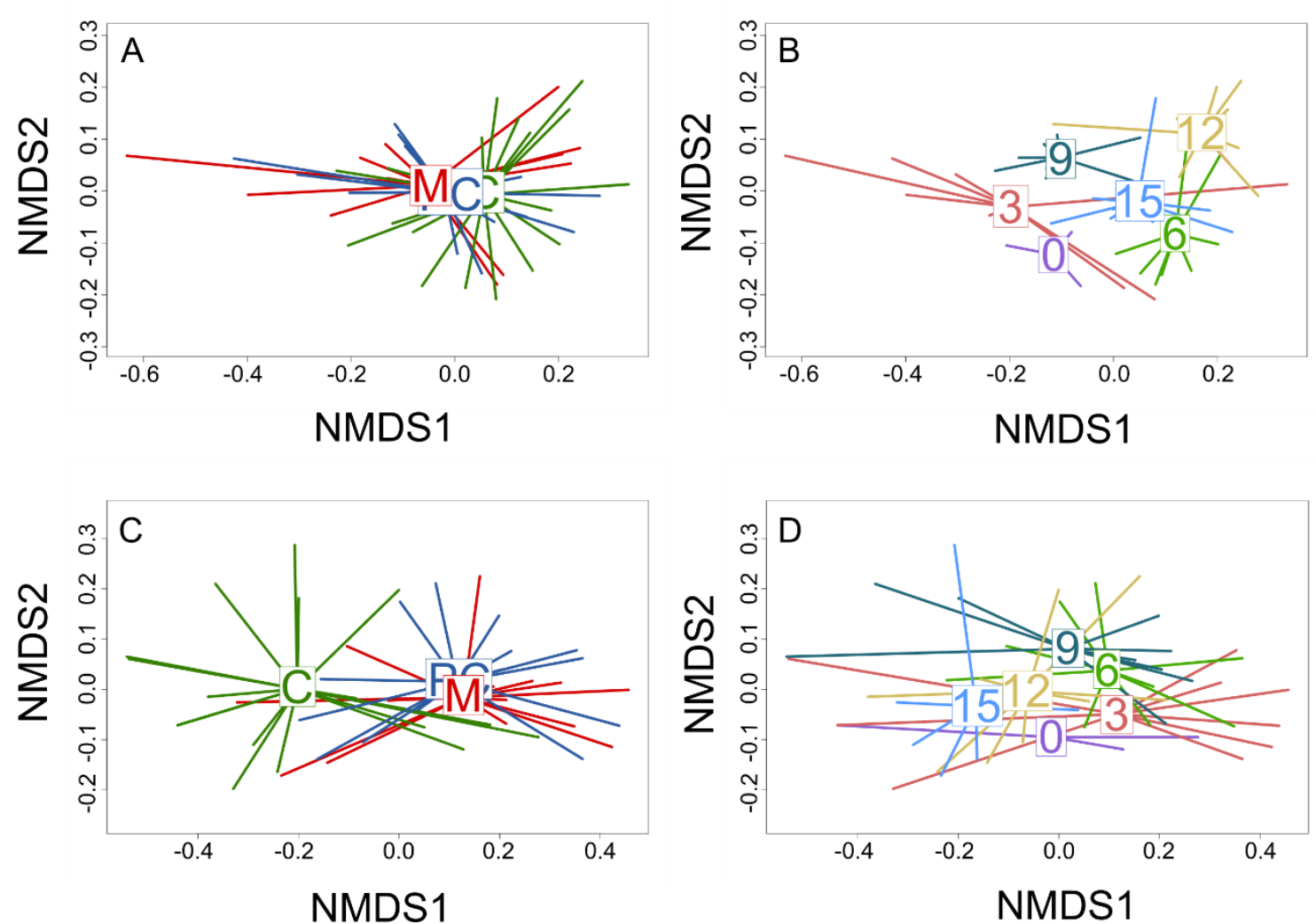

Fig. 6: Results from the Nonmetric Multidimensional Scaling (NMDS) analysis on the seagrass meadows (A and B) and the bare sediment habitats (C and D), showing the dispersion of the samples (lines) around the centroid of each group, by treatment (A and C): M: medusae, PC: procedure control, C: control; and by sampling time in hours (B and D).

The results of the two-factor multivariate linear model (mvabund), for each habitat, were consistent with the results of the PERMANOVA (reported above). In the seagrass meadows, the treatment alone did not affect the community composition, but it was significant when combined with sampling time (significant interaction, Dev $=175.6, \mathrm{p}$-value $=0.007$ ). On the bare sediment, both the treatment and sampling time affected the community composition ( $\mathrm{p}$-value $<0.05$ ).

This analysis allowed the identification of the taxa that contributed most to the observed differences between treatments (Table 4): Bittium sp. in the seagrass meadows and Tricolia sp., Hexaplex sp., Tritia sp. and Ruditapes sp. on the bare sediment habitats (Fig. 7). These organisms exhibited higher abundances in M and PC at $3 \mathrm{~h}$ but no difference of abundances between $\mathrm{M}$ and

436 PC treatments were observed $\left(\mathrm{P}_{\mathrm{adj}}>0.05\right)$. Indeed, differences between $\mathrm{M}$ and PC treatments 437 were only observed for Tritia sp. $\left(\mathrm{P}_{\text {adj }}=0.04\right)$, which showed higher abundances for $\mathrm{M}$ during the 438 first $9 \mathrm{~h}$ of the study period (up to $14.9 \pm 3.6 \times 10$ ind.m ${ }^{-2}$, Fig. 7D). Therefore, although Bittium 
439 sp. (in seagrass meadows), Hexaplex sp., Tricolia sp., and Ruditapes sp. (on the bare sediment)

440 appeared to have positively responded to the presence of jelly-falls, especially at $3 \mathrm{~h}$, only the

441 Tritia sp. (on the bare sediment) revealed statistical evidence of a positive response to the presence

442 of dead A. coerulea medusae on the bottom.

Table 4: Results of the 'species-by-species' two-factor multivariate linear model (ManyGLM), with the terms and the significance of each term (adjusted p-values) in the model (treatment, sampling time, and interaction). Bold values indicate significant differences at $\alpha=0.05$.

\begin{tabular}{|c|c|c|c|c|c|c|}
\hline \multirow[b]{2}{*}{ Seagrass meadows } & \multicolumn{2}{|c|}{ Treatment } & \multicolumn{2}{|c|}{ Sampling time } & \multicolumn{2}{|c|}{$\begin{array}{c}\text { Treatment: Sampling } \\
\text { time }\end{array}$} \\
\hline & Dev & $\mathbf{P}_{\text {adj }}$ & Dev & $\mathbf{P}_{\text {adj }}$ & Dev & $\mathbf{P}_{\text {adj }}$ \\
\hline Cerastoderma sp. & 0.433 & 0.982 & 26.982 & 0.008 & 5.557 & 0.945 \\
\hline Gastrana sp. & 0.676 & 0.982 & 18.624 & 0.055 & 5.012 & 0.945 \\
\hline Loripes sp. & 1.876 & 0.958 & 60.183 & 0.001 & 19.451 & 0.359 \\
\hline Ruditapes sp. & 0.249 & 0.982 & 41.143 & 0.001 & 9.649 & 0.918 \\
\hline Bittium sp. & 7.987 & 0.449 & 41.265 & 0.001 & 40.549 & 0.001 \\
\hline Cerithium sp. & 2.013 & 0.958 & 7.663 & 0.768 & 4.902 & 0.945 \\
\hline Gibbula sp. & 6.677 & 0.548 & 20.578 & $\mathbf{0 . 0 3 0}$ & 25.757 & 0.100 \\
\hline Hexaplex sp. & 3.726 & 0.936 & 7.681 & 0.768 & 7.366 & 0.935 \\
\hline Jujubinus sp. & 0.000 & 1.000 & 0.000 & 1.000 & 0.000 & 1.000 \\
\hline Rissoa sp. & 3.409 & 0.941 & 9.682 & 0.555 & 8.813 & 0.918 \\
\hline Tricolia sp. & 7.972 & 0.449 & 6.472 & 0.768 & 7.810 & 0.935 \\
\hline Gastropoda NI & 0.000 & 1.000 & 0.000 & 1.000 & 0.000 & 1.000 \\
\hline Sphaeroma sp. & 2.843 & 0.941 & 11.816 & 0.381 & 15.583 & 0.582 \\
\hline Microdeutopus sp. & 3.262 & 0.941 & 4.412 & 0.850 & 8.919 & 0.918 \\
\hline Cirratulidae & 2.402 & 0.941 & 3.750 & 0.850 & 0.001 & 0.945 \\
\hline Glyceridae & 0.000 & 1.000 & 0.000 & 1.000 & 0.000 & 1.000 \\
\hline Tritia sp. & 1.452 & 0.958 & 14.332 & 0.214 & 16.203 & 0.582 \\
\hline \multicolumn{7}{|l|}{ Bare sediment } \\
\hline Cerastoderma sp. & 0.391 & 0.843 & 7.686 & 0.661 & 9.641 & 0.794 \\
\hline Gastrana sp. & 0.000 & 1.000 & 0.000 & 1.000 & 0.000 & 1.000 \\
\hline Loripes sp. & 1.764 & 0.713 & 3.137 & 0.948 & 6.730 & 0.794 \\
\hline Ruditapes sp. & 24.699 & 0.001 & 18.268 & 0.036 & 8.739 & 0.794 \\
\hline Bittium sp. & 9.271 & 0.109 & 32.619 & 0.001 & 20.626 & 0.140 \\
\hline Cerithium sp. & 6.039 & 0.395 & 2.509 & 0.948 & 4.872 & 0.794 \\
\hline Gibbula sp. & 7.441 & 0.251 & 15.723 & 0.067 & 8.634 & 0.794 \\
\hline Hexaplex sp. & 12.639 & 0.024 & 3.401 & 0.948 & 1.955 & 0.794 \\
\hline Jujubinus sp. & 6.794 & 0.313 & 17.327 & 0.048 & 10.152 & 0.794 \\
\hline Rissoa sp. & 8.154 & 0.177 & 22.319 & 0.014 & 19.967 & 0.145 \\
\hline Tricolia sp. & 4.182 & 0.576 & 16.865 & 0.051 & 25.929 & 0.046 \\
\hline Gastropoda NI & 4.280 & 0.576 & 15.542 & 0.067 & 2.883 & 0.794 \\
\hline Sphaeroma sp. & 0.000 & 1.000 & 0.000 & 1.000 & 0.000 & 1.000 \\
\hline Microdeutopus sp. & 4.852 & 0.567 & 5.147 & 0.892 & 0.000 & 0.830 \\
\hline Cirratulidae & 4.720 & 0.567 & 24.968 & $\mathbf{0 . 0 0 3}$ & 8.259 & 0.794 \\
\hline
\end{tabular}




\begin{tabular}{lcccccc}
\hline Glyceridae & 3.377 & 0.596 & 5.275 & 0.892 & 10.271 & 0.794 \\
Tritia sp. & 21.770 & $\mathbf{0 . 0 0 1}$ & 12.924 & 0.136 & 12.333 & 0.638 \\
\hline
\end{tabular}
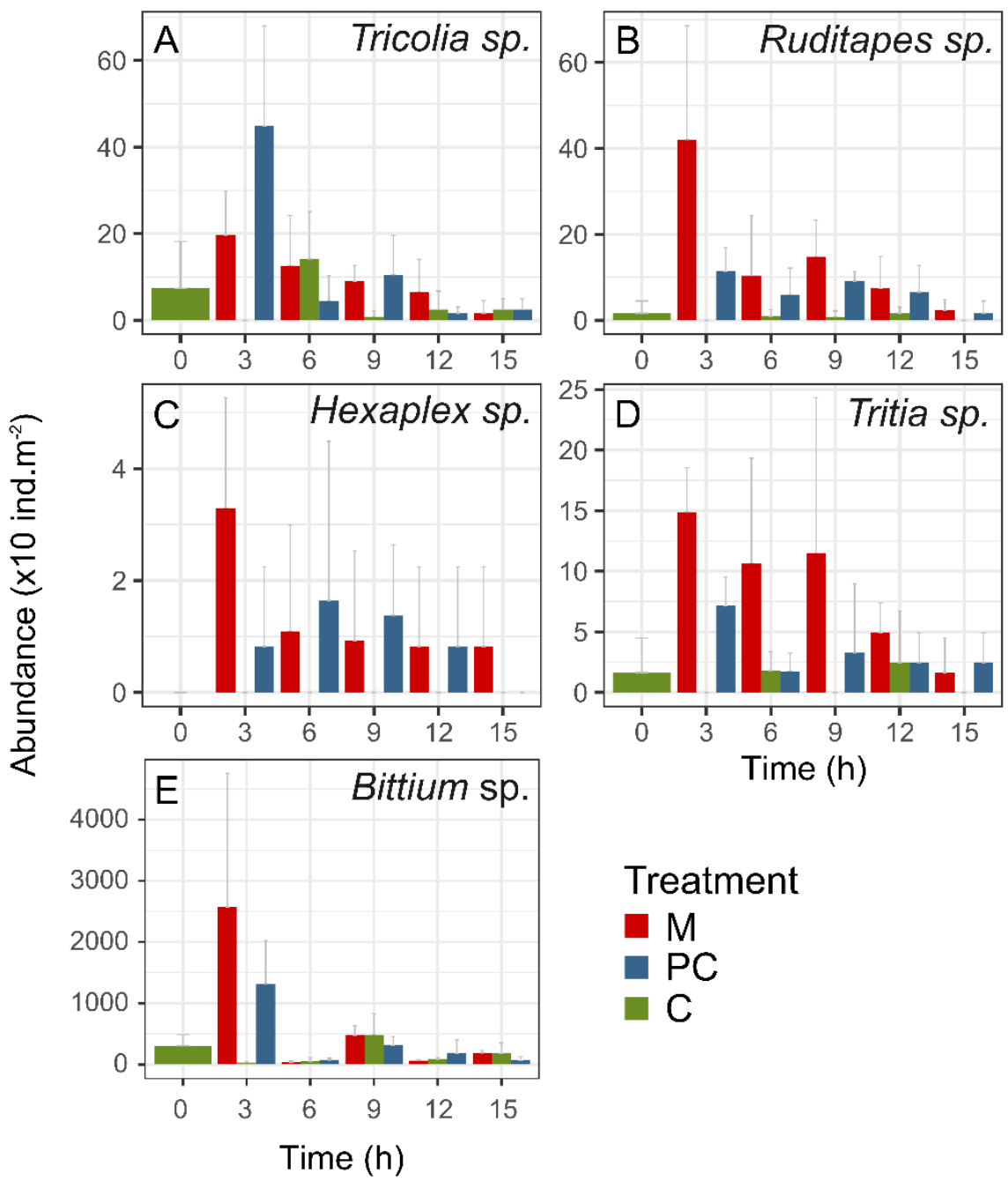

Fig. 7: Abundance of the macrobenthic organisms which showed significant contributions to the observed differences among treatments and sampling time (ManyGLM) on bare sediment (A to D) and seagrass meadows (E) habitats. Note the differences in scale between graphs.

\section{Discussion}

4.1. The contribution of macrobenthic consumption to the fast degradation of jellyfish in Thau

Local scavengers might play a significant role in jelly-falls disappearance from the benthic environments by consuming jellyfish biomass that sinks or accumulates on the seafloor 
communities appear to have a limited impact on the biomass loss of dead A. coerulea medusae in the Thau lagoon. This is supported by the lack of significant differences in jellyfish biomass loss rates between the Micro and Macro scenarios and by the limited response of the benthic communities to the addition of jelly-falls to the seabed (except for one particular taxon, the Tritia sp.). Therefore, our results suggest that, in the Thau lagoon, jelly-falls are likely mainly degraded by microorganisms (e.g. bacteria, microzooplankton, and small mesozooplankton species) with a limited contribution of macrobenthic consumption in their disappearance.

The in situ degradation of $A$. coerulea medusae in the Thau lagoon was very fast, with biomass loss rates ranging from 0.06 to $0.24 \mathrm{~h}^{-1}\left(1.42\right.$ to $\left.5.8 \mathrm{~d}^{-1}\right)$ and a $99 \%$ degradation of dead jellyfish biomass in about 19 hours on bare sediments and less than 3.5 days on seagrass meadows. High jellyfish biomass loss rates have been previously reported, with complete degradation of fresh dead jellyfish occurring within 5 to 14 days (Titelman et al. 2006; West et al. 2009; Qu et al. 2015). These rapid degradations of dead jellyfish (mainly by microbial decomposition) were attributed to the biochemical composition of their tissues, with a high proportion of proteins, low $\mathrm{C}: \mathrm{N}$ ratio, and lack of hard structures, providing high-quality substrate for specific bacteria (Titelman et al. 2006; Tinta et al. 2012, 2020). Indeed, simulated scenarios performed with Aurelia aurita showed that about half of its dead organic matter is instantly available as dissolved organic matter and rapidly consumed by microbes (within 1.5 days, Tinta et al., 2020). Decay rates are also known to vary with seawater temperature and jellyfish size (Titelman et al. 2006; Lebrato et al. 2011, 2012). Temperature is probably one of the most important factors driving differences in jellyfish decay rates (Lebrato et al. 2011). In the Thau lagoon, the collapse of the A. coerulea bloom coincides with the peak of summer temperatures $\left(>20^{\circ} \mathrm{C}\right.$; Marques et al. 2015a). This might promote fast medusae degradation by the microbenthos, but also in the water column (Tinta et al. 2020), thereby reducing the amount of jellyfish biomass that reaches the sea bed. The biomass loss rates observed in Thau are in the range of those decay rates estimated for tropical shallow environments, where less than one day is required to decompose $99 \%$ of jellyfish organic matter (Lebrato et al. 2011). However, degradation rates also depend on the initial medusae biomass, with smaller individuals decaying faster than larger ones (Titelman et al. 2006). 
The medusae of A. coerulea in Thau are usually smaller than those of other Aurelia species

490 (Marques et al. 2015a) or scyphozoans (Pitt 2000; Fuentes et al. 2011; Prieto et al. 2013).

491 Therefore, it is a combination of small-sized medusae and high local temperature which likely

492 promotes fast biomass loss rates of jelly-falls in this shallow ecosystem, through the action of 493 microorganisms.

494 We initially hypothesised that differences in macrobenthic community composition associated 495 with different habitats would have a distinct impact on the biomass loss rate of the jelly-falls. The 496 consumption of dead jellyfish by macroorganisms can be expected to be more important in 497 habitats with lower food availability (Sweetman et al. 2014) since local organisms depend on less 498 frequent inputs of new sources of organic matter (Holmer et al. 2004). Indeed, in the Thau lagoon 499 and as expected (Thouzeau et al. 2007; Rueda et al. 2009), macrobenthic communities differed between the two tested habitats, and higher biomass loss rates were observed on bare sediments, where the amount of available organic matter is lower (Plus et al. 2003). Furthermore, it was on bare sediments that the only macrobenthic organism was significantly attracted by jelly-falls (gastropods from the Tritia genus). These results suggest a possible contribution of the macroorganisms consumption to the disappearance of A. coerulea jelly-falls in the lagoon. However, these results must be considered with caution since the effect of the habitat in our study was not completely independent from the initial biomass of $A$. coerulea used in each experiment (higher on the seagrass meadows than on the bare sediment), which has been shown to affect jellyfish decay rates (Titelman et al. 2006). The experiments were performed on different days and, although individuals were randomly selected, the captivity time between experiments might have induced a bias on the initial weight of the medusae. Furthermore, although this was not tested

511 in the present work, this captivity time might have also affected the biochemical composition of jellyfish tissues, potentially affecting our results.

513 Within each habitat, our results suggest a limited consumption of jelly-falls by macrobenthic 514 organisms. On the bare sediments, the results from the degradation experiment showed that 515 jellyfish decay rates were not affected by the accessibility scenarios, while on the seagrass meadows, the biomass loss of dead medusae was even faster for the Micro than for the Macro 
517 scenario, which was unexpected. This might partially be caused by our experimental setup.

518 Indeed, the small mesh of the net bags $(200 \mu \mathrm{m})$ used in this scenario, might have promoted the

519 physical retention of microorganisms, protecting them against local currents, thereby avoiding

520 their advection and dilution in the surrounding water. Moreover, by eliminating large organisms,

521 the retention of microorganisms within the bag might have modified the trophic interactions, by

522 simultaneously providing high concentrations of organic matter and decreasing the grazing

523 pressure on microorganisms, boosting their proliferation. If this is true, it is possible that the decay

524 rates obtained for the Micro scenario are greater than those actually occurring in the lagoon.

525 The results from our second experiment corroborate the limited contribution of macrobenthic

526 organisms in the disappearance of jelly-falls in Thau. The lack of significant difference in

527 community composition among the M and PC treatments indicates that the addition of jelly-falls

528 to the seabed did not significantly disturb the community composition, either by attracting or

529 repelling organisms. However, the species-specific analysis (i.e. ManyGLM), revealed potential

530 positive responses of some particular taxa. Among those are the Bittium sp. in the seagrass

531 meadows and the Tritia sp., Hexaplex sp., and Ruditapes sp. on the bare sediment. Indeed, peaks

532 of their abundance were recorded, especially, for the $\mathrm{M}$ treatment at $3 \mathrm{~h}$, which co-occurred with

533 the maximum in jellyfish biomass loss rates in our study. This might suggest a limited but still

534 possible contribution of these macroorganisms consumption to the disappearance of dead

535 medusae in the lagoon. Nevertheless, only the Tritia sp. (Nassariidae family; Galindo et al., 2016)

536 revealed significant differences between the $\mathrm{M}$ and the PC treatments, indicating that, jelly-falls

537 only significantly attracted this particular species, as also reported by Chelsky et al. (2016).

538 Nassariidae species are common on soft sediment habitats and reported as herbivorous,

539 carnivorous, but mainly as scavengers, feeding opportunistically on the available dead organic

540 matter (Morton 2011). These organisms rapidly detect carrions from long distances and move fast

541 towards the carcasses, but they leave it once they are satiated to avoid potential predators (Morton

542 2011). They appear to eat large amounts of organic matter (20 to $60 \%$ of their weight) in as fast

543 as 8 minutes (Morton 2011; Lucena et al. 2012) and the amount of time they spend on feeding

544 appears to be a function of their hunger, with individuals living in habitats with lower food supply, 
eating a larger amount of food and spending more time feeding (Morton and Chan 1999). This might explain the peak of Tritia sp. abundance observed during the first hours of the experiment on the bare sediment habitat. Therefore, although our results suggest a limited consumption of $A$. coerulea carcasses by the macrobenthos after the annual blooms of the jellyfish in Thau, the scavenging activity of the gastropods from the Tritia genus might still contribute to the fast disappearance of its jelly-falls on the lagoon's bare sediment habitats.

\subsection{Potential ecological impacts of jellyfish degradation in Thau}

Our results suggest that the rapid biomass loss of A. coerulea jelly-falls in the Thau lagoon is mostly caused by a fast degradation of its dead medusae by local microorganisms, with a possible contribution of some particular species of scavenger on the bare sediment habitat. This might have several ecological implications in Thau, but also in other shallow coastal habitats.

The increase of dissolved inorganic nutrients in the surroundings of decaying jellyfish might enhance the local phytoplankton and algal production through direct assimilation of dissolved inorganic compounds (Pitt et al. 2009; Blanchet et al. 2015). Likewise, bacterial production might be enhanced during the jellyfish degradation process (Tinta et al. 2010, 2012, 2020), which represents an important food source for microzooplankton (Rassoulzadegan and Sheldon 1986). This supports the hypothesis that the available energy of jelly-falls can be directly (if consumed by some scavengers) or indirectly (through microorganisms) transferred to higher trophic levels. However, the ecological consequences of the rapid degradation of A. coerulea blooms by the bacterial community in Thau might also be negative. During the summer, anoxic crisis episodes, known as 'malaïgues', occasionally occur in the lagoon. They are caused by the bacterial degradation of high concentrations of organic matter as the combination of high water temperatures, weak winds, and important water residence times which promotes stratification of the water column and decreases oxygen exchanges at the surface or with the sea (Harzallah and Chapelle 2002). During jellyfish degradation, large amounts of highly bioavailable dissolved organic matter are released and quickly metabolized by the microbial community, decreasing the dissolved oxygen concentrations in the vicinity of jellyfish carcasses (West et al. 2009; Pitt et al. 
2009; Sweetman et al. 2016; Chelsky et al. 2016; Guy-Haim et al. 2020). Therefore, the collapse of the A. coerulea bloom in the early summer might amplify the magnitude of summer anoxic crises, potentially leading to massive benthic community mortalities. Lastly, the summer collapse of the jellyfish bloom and its degradation by local bacteria might partially contribute to the summer mortalities of the cultivated oyster Crassostrea gigas that sporadically occur in Thau (Pernet et al. 2012). Indeed, the bacterial degradation of A. coerulea medusae has been shown to enhance abundances of Vibrio spp. in the surrounding water (Tinta et al. 2012; Blanchet et al. 2015), and peaks of these microorganisms (from Vibrionacea family) have been associated with C. gigas mortalities (Pernet et al. 2012; Cantet et al. 2013). Although this scenario is very speculative, it needs to be investigated, because shellfish farming is the most important local economic activity in the lagoon, and shellfish mortality events have dramatic consequences on the local economy (Pernet et al. 2012).

\section{Conclusion}

Evaluating the ecological impacts of jellyfish blooms requires identifying the fate of their organic matter, i.e. whether they are scavenged by demersal or benthic predators, decomposed by microorganisms, or both. In Thau, the absence of large accumulations of dead medusae of $A$. coreulea on the seafloor probably partially results from their ingestion by several local fish species (Marques et al. 2019) and rapid degradation in the water column (Tinta et al. 2020). However, we show that, upon their arrival on the sea bed, their fast biomass loss is mainly caused by their rapid degradation by local microorganisms, favoured by the high local summer temperatures and the small size of the medusae. Ingestion by benthic scavengers is possible but limited. Therefore the collapse of the jellyfish blooms in the lagoon has a limited impact on its macrobenthic communities. Instead, they have the potential to significantly modify local biogeochemical cycles, reshape ecosystem functioning and, ultimately, affect ecosystem services with important implications on several economic activities. This supports the need for further 
600 investigations on jellyfish degradation in coastal lagoons and calls for incorporating this process 601 in ecosystem-based models. 
603 We thank Sebastien Colantoni, Perline Bastide, and Sadjia Belkacemi for their collaboration 604 during field and laboratory work. We also thank Prof. Stephan Baghdiguian for his precious help 605 during molluscs' identification. We also thank the comments of the reviewers which largely 606 contributed to the improvement of the manuscript.

607 This work was funded by MARBEC laboratory (internal resources).

608 The authors declare that they have no competing interests.

609

610 
Anderson, M. J. 2017. Permutational Multivariate Analysis of Variance (PERMANOVA), p. 115. In Wiley StatsRef: Statistics Reference Online. John Wiley \& Sons, Ltd.

Ates, R. M. L. 2017. Benthic scavengers and predators of jellyfish, material for a review. Plankton and Benthos Research 12: 71-77. doi:10.3800/pbr.12.71

Billett, D. S. M., B. J. Bett, C. L. Jacobs, I. P. Rouse, and B. D. Wigham. 2006. Mass deposition of jellyfish in the deep Arabian Sea. Limnology and Oceanography 51: 2077-2083. doi:10.4319/lo.2006.51.5.2077

Blanchet, M., O. Pringault, M. Bouvy, and others. 2015. Changes in bacterial community metabolism and composition during the degradation of dissolved organic matter from the jellyfish Aurelia aurita in a Mediterranean coastal lagoon. Environ Sci Pollut Res 22: 13638-13653. doi:10.1007/s11356-014-3848-x

Bonnet, D., J.-C. Molinero, T. Schohn, and M. N. Daly-Yahia. 2012. Seasonal changes in the population dynamics of Aurelia aurita in Thau lagoon. Cahier de Biologie Marine 53: $343-347$.

Bos, A. R., E. Cruz-Rivera, and A. M. Sanad. 2017. Herbivorous fishes Siganus rivulatus (Siganidae) and Zebrasoma desjardinii (Acanthuridae) feed on Ctenophora and Scyphozoa in the Red Sea. Mar Biodiv 47: 243-246. doi:10.1007/s12526-016-0454-9

Cantet, F., D. Hervio-Heath, A. Caro, and others. 2013. Quantification of Vibrio parahaemolyticus, Vibrio vulnificus and Vibrio cholerae in French Mediterranean coastal lagoons. Research in Microbiology 164: 867-874. doi:10.1016/j.resmic.2013.06.005

Cardona, L., I. Á. de Quevedo, A. Borrell, and A. Aguilar. 2012. Massive Consumption of Gelatinous Plankton by Mediterranean Apex Predators. PLOS ONE 7: e31329. doi:10.1371/journal.pone.0031329

Chelsky, A., K. A. Pitt, A. J. P. Ferguson, W. W. Bennett, P. R. Teasdale, and D. T. Welsh. 2016. Decomposition of jellyfish carrion in situ: Short-term impacts on infauna, benthic nutrient fluxes and sediment redox conditions. Science of The Total Environment 566567: 929-937. doi:10.1016/j.scitotenv.2016.05.011 
Condon, R. H., D. K. Steinberg, P. A. del Giorgio, and others. 2011. Jellyfish blooms result in a major microbial respiratory sink of carbon in marine systems. Proceedings of the National Academy of Sciences 108: 10225-10230. doi:10.1073/pnas.1015782108

D’Angelo, G., and S. Gargiullo. 1978. Guida alle conchiglie mediterranee: Conoscerle, cercarle, collezionarle, I. S. Gruppo Editoriale Fabbri, Bompiani [ed.]. Fabbri.

Dunlop, K. M., D. O. B. Jones, and A. K. Sweetman. 2017. Direct evidence of an efficient energy transfer pathway from jellyfish carcasses to a commercially important deep-water species. Scientific Reports 7: 17455. doi:10.1038/s41598-017-17557-x

Fauvel, P. 1923. Faune de France. Polychetes Errantes, P. Lechevalier [ed.].

Fauvel, P. 1927. Faune de France. Polychetes Errantes, P. Lechevalier [ed.].

650

Fiandrino, A., A. Giraud, S. Robin, and C. Pinatel. 2012. Validation d'une méthode d'estimation des volumes d'eau échangés entre la mer et les lagunes et définition d'indicateurs hydrodynamiques associés.

Frost, J. R., C. A. Jacoby, T. K. Frazer, and A. R. Zimmerman. 2012. Pulse perturbations from bacterial decomposition of Chrysaora quinquecirrha (Scyphozoa: Pelagiidae). Hydrobiologia 690: 247-256. doi:10.1007/s10750-012-1042-z

Fuentes, V., I. Straehler-Pohl, D. Atienza, and others. 2011. Life cycle of the jellyfish Rhizostoma pulmo (Scyphozoa: Rhizostomeae) and its distribution, seasonality and inter-annual variability along the Catalan coast and the Mar Menor (Spain, NW Mediterranean). Marine Biology 158: 2247-2266. doi:10.1007/s00227-011-1730-7

Galindo, L. A., N. Puillandre, J. Utge, P. Lozouet, and P. Bouchet. 2016. The phylogeny and systematics of the Nassariidae revisited (Gastropoda, Buccinoidea). Molecular Phylogenetics and Evolution 99: 337-353. doi:10.1016/j.ympev.2016.03.019

Guy-Haim, T., M. Rubin-Blum, E. Rahav, N. Belkin, J. Silverman, and G. Sisma-Ventura. 2020. The effects of decomposing invasive jellyfish on biogeochemical fluxes and microbial dynamics in an ultra-oligotrophic sea. Biogeosciences 17: 5489-5511. doi:10.5194/bg$17-5489-2020$ 
Harzallah, A., and A. Chapelle. 2002. Contribution of climate variability to occurrences of anoxic crises 'malaïgues' in the Thau lagoon (southern France). Oceanologica Acta 25: 79-86.

Hays, G. C., T. K. Doyle, and J. D. R. Houghton. 2018. A Paradigm Shift in the Trophic Importance of Jellyfish? Trends in Ecology \& Evolution 33: 874-884. doi:10.1016/j.tree.2018.09.001

Holmer, M., C. M. Duarte, H. T. S. Boschker, and C. Barrón. 2004. Carbon cycling and bacterial carbon sources in pristine and impacted Mediterranean seagrass sediments. Aquatic Microbial Ecology 36: 227-237. doi:10.3354/ame036227

Kindt, R., and R. Coe. 2005. Tree diversity analysis. A manual and software for common statistical methods for ecological and biodiversity studies., World Agroforestry Centre (ICRAF).

Lebrato, M., and D. O. B. Jones. 2009. Mass deposition event of Pyrosoma atlanticum carcasses off Ivory Coast (West Africa). Limnology and Oceanography 54: 1197-1209. doi:10.4319/lo.2009.54.4.1197

Lebrato, M., P. de J. Mendes, D. K. Steinberg, J. E. Cartes, B. M. Jones, L. M. Birsa, R. Benavides, and A. Oschlies. 2013. Jelly biomass sinking speed reveals a fast carbon export mechanism. Limnology and Oceanography 58: 1113-1122. doi:https://doi.org/10.4319/lo.2013.58.3.1113

Lebrato, M., M. Pahlow, J. R. Frost, M. Küter, P. de J. Mendes, J.-C. Molinero, and A. Oschlies. 2019. Sinking of Gelatinous Zooplankton Biomass Increases Deep Carbon Transfer Efficiency Globally. Global Biogeochemical Cycles 33: 1764-1783. doi:https://doi.org/10.1029/2019GB006265

Lebrato, M., M. Pahlow, A. Oschlies, K. A. Pitt, D. O. B. Jones, J. C. Molinero, and R. H. Condon. 2011. Depth attenuation of organic matter export associated with jelly falls. Limnology and Oceanography 56: 1917-1928. doi:10.4319/lo.2011.56.5.1917

Lebrato, M., K. A. Pitt, A. K. Sweetman, and others. 2012. Jelly-falls historic and recent observations: A review to drive future research directions. Hydrobiologia 690: 227-245. doi:10.1007/s10750-012-1046-8 
Lilley, M. K. S., S. E. Beggs, T. K. Doyle, V. J. Hobson, K. H. P. Stromberg, and G. C. Hays. 2011. Global patterns of epipelagic gelatinous zooplankton biomass. Marine Biology 158: 2429-2436. doi:10.1007/s00227-011-1744-1

Lucena, J., C. Meirelles, and H. Matthews-Cascon. 2012. Feeding behavior of Nassarius vibex (Gasteropoda: Nassariidae). Arquivos de Ciências do Mar 45: 60-67. doi:10.32360/acmar.v45i2.134

Luo, J. Y., R. H. Condon, C. A. Stock, C. M. Duarte, C. H. Lucas, K. A. Pitt, and R. K. Cowen. 2020. Gelatinous Zooplankton-Mediated Carbon Flows in the Global Oceans: A DataDriven Modeling Study. Global Biogeochemical Cycles 34: e2020GB006704. doi:https://doi.org/10.1029/2020GB006704

Marques, R., S. Albouy-Boyer, F. Delpy, C. Carré, É. Le Floc'h, C. Roques, J.-C. Molinero, and D. Bonnet. 2015a. Pelagic population dynamics of Aurelia sp. in French Mediterranean lagoons. Journal of Plankton Research 37: 1019-1035. doi:10.1093/plankt/fbv059

Marques, R., M. Cantou, S. Soriano, J.-C. Molinero, and D. Bonnet. 2015b. Mapping distribution and habitats of Aurelia sp. polyps in Thau lagoon, north-western Mediterranean Sea (France). Mar Biol 162: 1441-1449. doi:10.1007/s00227-015-2680-2

Marques, R., A. M. Darnaude, S. Crochemore, C. Bouvier, and D. Bonnet. 2019. Molecular approach indicates consumption of jellyfish by commercially important fish species in a coastal Mediterranean lagoon. Marine Environmental Research 152: 104787. doi:10.1016/j.marenvres.2019.104787

Morton, B. 2011. Behaviour of Nassarius bicallosus (Caenogastropoda) on a northwestern Western Australian surf beach with a review of feeding in the Nassariidae. Molluscan Research 31: 89-94.

Morton, B., and K. Chan. 1999. Hunger rapidly overrides the risk of predation in the subtidal scavenger Nassarius siquijorensis (Gastropoda: Nassariidae): an energy budget and a comparison with the intertidal Nassarius festivus in Hong Kong. Journal of Experimental Marine Biology and Ecology 240: 213-228. doi:10.1016/S0022-0981(99)00060-X 
Newton, A., J. Icely, S. Cristina, and others. 2014. An overview of ecological status, vulnerability and future perspectives of European large shallow, semi-enclosed coastal systems, lagoons and transitional waters. Estuarine, Coastal and Shelf Science 140: 95-122. doi:10.1016/j.ecss.2013.05.023

Oksanen, A. J., F. G. Blanchet, M. Friendly, and others. 2019. vegan: Community Ecology Package.

Pernet, F., J. Barret, P. Le Gall, C. Corporeau, L. Dégremont, F. Lagarde, J. Pépin, and N. Keck. 2012. Mass mortalities of Pacific oysters Crassostrea gigas reflect infectious diseases and vary with farming practices in the Mediterranean Thau lagoon, France. Aquaculture Environment Interactions 2: 215-237. doi:10.3354/aei00041

Pinheiro, J., Bates, S. DebRoy, D. Sarkar, and R Core Team. 2019. nlme: Linear and Nonlinear Mixed Effects Models.

Pitt, K. A. 2000. Life history and settlement preferences of the edible jellyfish Catostylus mosaicus (Scyphozoa: Rhizostomeae). Marine Biology 136: 269-279. doi:10.1007/s002270050685

Pitt, K. A., A. C. Budarf, J. G. Browne, and R. H. Condon. 2014. Bloom and Bust: Why Do Blooms of Jellyfish Collapse?, p. 79-103. In K.A. Pitt and C.H. Lucas [eds.], Jellyfish Blooms. Springer Netherlands.

Pitt, K. A., and M. J. Kingsford. 2003. Temporal and spatial variation in recruitment and growth of medusae of the jellyfish, Catostylus mosaicus (Scyphozoa: Rhizostomeae). Marine and Freshwater Research 54: 117. doi:10.1071/MF02110

Pitt, K. A., D. T. Welsh, and R. H. Condon. 2009. Influence of jellyfish blooms on carbon, nitrogen and phosphorus cycling and plankton production. Hydrobiologia 616: 133-149. doi:10.1007/s10750-008-9584-9

Plus, M., A. Chapelle, P. Lazure, and others. 2003. Modelling of oxygen and nitrogen cycling as a function of macrophyte community in the Thau lagoon. Continental Shelf Research 23: 1877-1898. doi:10.1016/j.csr.2003.03.001 
Prieto, L., A. Armani, and D. Macías. 2013. Recent strandings of the giant jellyfish Rhizostoma luteum Quoy and Gaimard, 1827 (Cnidaria: Scyphozoa: Rhizostomeae) on the Atlantic and Mediterranean coasts. Marine Biology 160: 3241-3247. doi:10.1007/s00227-013$2293-6$

Purcell, J. E. 2012. Jellyfish and Ctenophore Blooms Coincide with Human Proliferations and Environmental Perturbations. Annual Review of Marine Science 4: 209-235. doi:10.1146/annurev-marine-120709-142751

Qu, C.-F., J.-M. Song, N. Li, X.-G. Li, H.-M. Yuan, L.-Q. Duan, and Q.-X. Ma. 2015. Jellyfish (Cyanea nozakii) decomposition and its potential influence on marine environments studied via simulation experiments. Marine Pollution Bulletin 97: 199-208. doi:10.1016/j.marpolbul.2015.06.016

Rassoulzadegan, F., and R. W. Sheldon. 1986. Predator-prey interactions of nanozooplankton and bacteria in an oligotrophic marine environment1. Limnology and Oceanography 31: 1010-1029. doi:10.4319/lo.1986.31.5.1010

Rueda, J. L., S. Gofas, J. Urra, and C. Salas. 2009. A highly diverse molluscan assemblage associated with eelgrass beds (Zostera marina L.) in the Alboran Sea: Micro-habitat preference, feeding guilds and biogeographical distribution. Scientia Marina 73: 679700. doi:10.3989/scimar.2009.73n4679

Sweetman, A. K., and A. Chapman. 2011. First observations of jelly-falls at the seafloor in a deep-sea fjord. Deep Sea Research Part I: Oceanographic Research Papers 58: 12061211. doi:10.1016/j.dsr.2011.08.006

Sweetman, A. K., and A. Chapman. 2015. First assessment of flux rates of jellyfish carcasses (jelly-falls) to the benthos reveals the importance of gelatinous material for biological Ccycling in jellyfish-dominated ecosystems. Frontiers in Marine Science 2: 1-7. doi:10.3389/fmars.2015.00047

Sweetman, A. K., A. Chelsky, K. A. Pitt, and others. 2016. Jellyfish decomposition at the seafloor rapidly alters biogeochemical cycling and carbon flow through benthic food-webs. Limnology and Oceanography 61: 1449-1461. doi:10.1002/lno.10310 
Sweetman, A. K., C. R. Smith, T. Dale, and D. O. B. Jones. 2014. Rapid scavenging of jellyfish carcasses reveals the importance of gelatinous material to deep-sea food webs. Proceedings of the Royal Society B: Biological Sciences 281: 20142210-20142210. doi:10.1098/rspb.2014.2210

Thouzeau, G., J. Grall, J. Clavier, and others. 2007. Spatial and temporal variability of benthic biogeochemical fluxes associated with macrophytic and macrofaunal distributions in the Thau lagoon (France). Estuarine, Coastal and Shelf Science 72: 432-446. doi:10.1016/j.ecss.2006.11.028

Tinta, T., T. Kogovšek, A. Malej, and V. Turk. 2012. Jellyfish Modulate Bacterial Dynamic and Community Structure. PLoS ONE 7: e39274. doi:10.1371/journal.pone.0039274

Tinta, T., T. Kogovšek, V. Turk, T. A. Shiganova, A. S. Mikaelyan, and A. Malej. 2016. Microbial transformation of jellyfish organic matter affects the nitrogen cycle in the marine water column - A Black Sea case study. Journal of Experimental Marine Biology and Ecology 475: 19-30. doi:10.1016/j.jembe.2015.10.018

Tinta, T., A. Malej, M. Kos, and V. Turk. 2010. Degradation of the Adriatic medusa Aurelia sp. by ambient bacteria. Hydrobiologia 645: 179-191. doi:10.1007/s10750-010-0223-x

Tinta, T., Z. Zhao, A. Escobar, K. Klun, B. Bayer, C. Amano, L. Bamonti, and G. J. Herndl. 2020. Microbial Processing of Jellyfish Detritus in the Ocean. Front. Microbiol. 11. doi:10.3389/fmicb.2020.590995

Titelman, J., L. Riemann, T. Sørnes, T. Nilsen, P. Griekspoor, and U. Båmstedt. 2006. Turnover of dead jellyfish: stimulation and retardation of microbial activity. Marine Ecology Progress Series 325: 43-58. doi:10.3354/meps325043

Wang, Y., U. Naumann, S. T. Wright, and D. I. Warton. 2012. mvabund - an R package for modelbased analysis of multivariate abundance data. Methods in Ecology and Evolution 3: 471474. doi:10.1111/j.2041-210X.2012.00190.x

Warton, D. I., S. T. Wright, and Y. Wang. 2012. Distance-based multivariate analyses confound location and dispersion effects. Methods in Ecology and Evolution 3: 89-101. doi:10.1111/j.2041-210X.2011.00127.x 
West, E. J., D. T. Welsh, and K. A. Pitt. 2009. Influence of decomposing jellyfish on the sediment oxygen demand and nutrient dynamics, p. 151-160. In K.A. Pitt and J.E. Purcell [eds.], Jellyfish Blooms: Causes, Consequences, and Recent Advances: Proceedings of the Second International Jellyfish Blooms Symposium, held at the Gold Coast, Queensland, Australia, 24-27 June, 2007. Springer Netherlands.

De Wit, R., H. Rey-Valette, J. Balavoine, V. Ouisse, and R. Lifran. 2017. Restoration ecology of coastal lagoons: new methods for the prediction of ecological trajectories and economic valuation. Aquatic Conservation: Marine and Freshwater Ecosystems 27: 137-157. doi:10.1002/aqc.2601

Yamamoto, J., M. Hirose, T. Ohtani, and others. 2008. Transportation of organic matter to the sea floor by carrion falls of the giant jellyfish Nemopilema nomurai in the Sea of Japan. Marine Biology 153: 311-317. doi:10.1007/s00227-007-0807-9

Zuur, A., E. N. Ieno, N. Walker, A. A. Saveliev, and G. M. Smith. 2009. Mixed Effects Models and Extensions in Ecology with R, Springer New York. 